\title{
Dissemination of evidence-based cancer control interventions among Catholic faith-based organizations: results from the CRUZA randomized trial
}

\author{
Jennifer D. Allen ${ }^{1,2^{*}}$, Maria Idalí Torres ${ }^{3}$, Laura S. Tom², Bryan Leyva ${ }^{4}$, Ana V. Galeas ${ }^{3}$ and Hosffman Ospino ${ }^{5}$
}

\begin{abstract}
Background: The CRUZA randomized trial tested the efficacy of an organizational-level intervention to increase the capacity of Catholic faith-based organizations (FBOs) serving Latinos to implement evidence-based strategies (EBS) for cancer control.

Methods: Thirty-one Catholic parishes were enrolled. Twenty were randomized to a "capacity enhancement" (CE) intervention and 11 to a "standard dissemination" (SD) condition. Each received a Program Implementation Manual and Toolkit of materials culturally adapted for FBOs with Latino audiences for five types of EBS recommended by the US Preventive Services Community Guide. CE parishes were offered a menu of capacity-building activities over a 3-month period, while SD parishes were provided a one-time consultation by an Intervention Specialist. Baseline and follow-up surveys compared the number and types of EBS offered.
\end{abstract}

Results: At baseline, only one parish had offered any cancer-related program in the prior year, yet a third (36\%) had offered some other type of health program or service. At post-intervention follow-up, all parishes offered a greater number of EBS. The only statistically significant difference between CE and SD groups was the number of parishes offering small media interventions (90\% in CE, $64 \%$ in SD; $p<0.05$ ).

Conclusions: All parishes increased the number of cancer control activities offered to their members. These findings suggest that Catholic parishes may already have capacity to implement EBS if they are appropriately adapted and packaged and may only require low levels of support to carry out programming. Further research is needed to examine the extent to which program offerings continued after the period of grant funding.

Trial registration: Clinicaltrials.gov NCT01740219.

Keywords: Latinos, Hispanics, Faith-based organizations, Catholic, Cancer screening, Evidence-based interventions, Implementation science, Organizational capacity, Capacity building, Community-based participatory research

\section{Background}

Community-based organizations' (CBOs) adoption and implementation of evidence-based strategies (EBS) for community-based cancer control is essential for translation of research into practice. Cancer control programs delivered by established $\mathrm{CBO}$ are

\footnotetext{
* Correspondence: jennifer.allen@tufts.edu

${ }^{1}$ Community Health Program and Department of Public Health and

Community Medicine, Tufts University, Medford, MA, USA

${ }^{2}$ Dana-Farber Cancer Institute, Boston, MA, USA

Full list of author information is available at the end of the article
}

generally more responsive to cultural and linguistic characteristics of the targeted populations and well utilized by community members [1]. However, limited studies have sought to understand existing and needed organizational capacities among CBOs to adopt and implement EBS [2-4]. Moreover, few rigorous trials have evaluated the efficacy of organizationallevel strategies, such as technical assistance, training, and mini-grants [2-4], for promoting EBS adoption and implementation among CBOs. 
Faith-based organizations (FBOs) are among the most trusted CBOs in Latino communities [5-7], long recommended as venues to reach populations marginalized from the mainstream health care system $[8,9]$. Several factors make FBOs natural partners for the delivery of EBS to promote health, including their ubiquity, access to large segments of the population (including medically underserved groups), infrastructures (e.g., health ministries, communication channels), support networks, and personnel resources (e.g., volunteers, lay leaders) [8-10]. Moreover, growing evidence suggests that "faith-based" programs (i.e., rooted in faith and religious teachings), or health interventions with cultural and religious adaptations (e.g., integration of prayer, religious traditions, rituals, writings) [11] may be particularly effective for religious audiences $[7,12,13]$.

Studies in the USA show that many FBOs view health as integral to their mission [8], yet only $10 \%$ sponsor any health-related programming [14]. While FBOs as a whole have a predilection for health programming, the low actual sponsorship of health programs suggests the need for interventions to enhance capacity of FBOs to adopt, implement, and sustain EBS for cancer control. Notably, Latino churches provide outstanding access to medically underserved Latino populations but are largely understudied as an organizational setting for cancer control [15-21]. The majority of published interventions in FBOs have been in Black churches $[9,13,22]$. Moreover, prior studies in FBOs have mainly considered strategies and approaches to promote individual-level behavior change $[9,13,22]$. Few studies have tested interventions to promote organizational-level change [23, 24], and of these, none have been among Latino churches. In this context, we designed the CRUZA study to evaluate the efficacy of an organizational-level capacity-enhancement intervention in facilitating implementation of EBS to promote cancer control among Latinos in FBOs.

\section{Methods}

\section{Study design}

CRUZA was a randomized trial with Catholic churches (hereafter referred to as "parishes") as the unit of randomization and intervention. CRUZA focused on parishes because more than half of Latinos in the USA self-identified as Catholic in 2013 [25], and nearly $50 \%$ of Catholic Latinos over age 50 report attending church one or more times a week [25]. Our goal was to test the efficacy of an intervention designed to build parishes' capacity to implement EBS for cancer control. The primary outcome was the difference in the mean number of EBS for cancer control across intervention conditions between baseline and follow-up. This study was approved by the Institutional Review Boards at the Harvard School of
Public Health and the University of Massachusetts, Boston. Study procedures and baseline findings have been described in detail elsewhere [26, 27].

\section{Community engagement}

CRUZA employed a community-based approach, in recognition of the importance of community expertise and engagement in all phases of the research process. Central to our cross-collaborative work was our community advisory committee (CAC), composed of key community stakeholders representing Latino community organizations, local government, cancer advocacy, and regional dioceses. The CAC's roles are described in detail elsewhere [26], but of relevance to this paper was the active role that CAC members played in contributing information regarding the acceptability and feasibility of various capacity-enhancement interventions. For example, given the challenges with trying to bring groups of representatives from participating $\mathrm{CE}$ parishes together for group training, they strongly recommended that we provide individual or on-site technical assistance to each of the sites. The CAC also played a critical role in the process of integrating religious principles and practices into our study messaging. The study's name-CRUZA-highlights this fact. The Spanish verb "CRUZA" means "to cross" and is symbolic of the study's cross-collaboration among FBOs, academic institutions, and CBOs. As a cognate of the word cross (cruz, in Spanish), "CRUZA" also evokes a clear Christian reference to healing and salvation-a key Catholic tenet.

Extensive formative research preceded the intervention trial, including 18 key informant interviews among Latino faith and community leaders, as well as eight focus groups totaling 67 Spanish-speaking parishioners. These formative research activities illuminated contextually appropriate strategies for engaging faith communities, developing capacity-building interventions, and adapting EBS for delivery in parishes, $[5,6,28,29]$. This work also informed the types and formats of small media and promotional materials that were included in the tool kit.

\section{Organizational recruitment, consent and randomization}

At the time of study initiation, there were 577 Catholic parishes located in Massachusetts [30]. Prior to parish recruitment, we contacted the four dioceses (administrative units of parishes in a geographic region) in the state, namely Boston, Fall River, Springfield, and Worcester to develop networks of collaboration with their heads (diocesan Bishops) and Hispanic Ministry directors. With the support of the diocesan structures, we utilized a two-stage sampling scheme to identify eligible parishes, and within them, eligible representatives to respond to organizational surveys. Individuals eligible to complete 
organizational surveys occupied formal roles within the FBO (e.g., pastor, business manager, director of Hispanic Ministry) as indicated by the pastor. Potential respondents received study materials and informed consent information by mail. Informed consent information was also reviewed prior to survey administration. This process is described in detail elsewhere [26, 27], but briefly, parishes that completed a baseline organizational survey between July and December 2012 were invited to participate in the CRUZA intervention trial [26]. Eligible parishes (a) were Roman Catholic; (b) located in Massachusetts; and (c) offered at least one Spanishlanguage mass per week. In addition, we required that eligible parishes not be scheduled for or undergoing closure or merger at the time of enrollment [31-33]. Prior to enrollment, pastors had to agree to meet or speak with CRUZA staff to review details of the intervention and evaluation and, if randomized to $\mathrm{CE}$ group, to designate a parish liaison to work with CRUZA's Intervention Specialists during the study period. Participating parishes were blocked on size of congregation ( $\geq 1500$ or $<1500$ parishioners) and randomized within blocks on a two-to-one ratio to the capacity enhancement (CE) or standard dissemination (SD) conditions using a random number generator. Randomization was conducted by the principal investigator.

\section{Intervention framework}

As an organizational-level intervention, CRUZA applied theoretical principles from the Consolidated Framework for Implementation Research (CFIR). Influences to implementation include (1) the characteristics of the intervention, (2) inner and outer organizational contexts, (3) characteristics of the implementer, and (4) clearly established implementation protocols [34]. Much time and energy were invested in adapting and packaging EBS for a Latino FBO setting, as CFIR suggests that interventions most likely to be utilized by organizations are those that are designed and packaged for the "end user" ("design quality and packaging"), are not overly complicated to implement ("complexity"), can be tried on a small scale ("trialability") at a low cost, and are modified to meet local needs ("adaptability"). This involved extensive formative research focusing on the relationship between Catholic religious traditions and teachings with health and health behaviors [5, 6, 28, 29].

The CFIR also posits that organizations that have leadership support and engagement, sufficient resources for implementation, and access to the knowledge and skills necessary for adoption/implementation of the innovation (i.e., "readiness for implementation") are more likely to adopt innovations. Moreover, organizations that have capacity for and collective receptivity to change (i.e., positive "implementation climate"); values consistent with the innovation (i.e., conducive "organizational culture"), and inter-organizational relationships that can facilitate innovation implementation are also more likely to adopt and/or implement innovations [34]. Thus, to implement a new program activity, an organization needs both infrastructure (i.e., policies, procedures, and resources) and the implementers (people with the expertise who will "champion" the program).

\section{Capacity-enhancement intervention}

Several published reviews have shown that skills-based training, technical assistance, and coalition building can enhance organizational capacity for specific innovations [35-38]. Various models for capacity building have been documented [39-48], but most include components such as provision of technical assistance; engagement of organizational members and leaders; partnership development; and training or education to provide information and skills for implementation. The CFIR model speaks directly to the "readiness" of an organization to implement an intervention, positing that leadership engagement (i.e., involvement of and sanction for the intervention from pastors), available resources (e.g., personnel, time, services), and access to information (e.g., Program Manual, Intervention Specialists) are key to successful implementation processes. In addition, the framework recognizes that the characteristics of individuals or groups charged with implementation may play a role in the success of such efforts (e.g., skills, self-efficacy).

In light of existing research, the CFIR model, input from our CAC and key Latino FBO leaders and in consideration of study resources (e.g., funding, study duration, number of CRUZA Intervention Specialists), we designed the CRUZA capacity-enhancement intervention to include (a) technical assistance, (b) formation of health committees or ministries, (c) facilitation of inter-institutional partnerships, and (d) skill-building workshops.

\section{Technical assistance}

CRUZA Intervention Specialists provided individual guidance to parish liaisons to impart knowledge and skills to implement EBS. Tailored to a parish liaison's skillset, interests, and communication preferences, technical assistance included coaching, information provision, and/or problem-solving offered in-person meetings, telephone, or email upon request.

\section{Health committees}

Health ministries are bodies within the parish that plan and execute health-related activities as part of the parish's overall mission [49]. In parishes with existing health ministries, we offered activities to expand their capacity to plan and execute EBS. In parishes without existing health ministries, CRUZA Intervention Specialists 
worked with the pastors to identify and recruit potential committee members and plan/facilitate meetings.

\section{Inter-institutional partnerships}

CRUZA Intervention Specialists facilitated inter-institutional partnerships between parishes and existing community resources such as local and state health departments, community health centers, hospitals, and social service agencies. Examples include brokering a parish's connections to health insurance navigators, mobile screening vans, and guest speakers for health-related workshops.

\section{Skill-building workshops}

Led by CRUZA Intervention Specialists, regional "faith and health" were half-day workshops for parish leaders and CRUZA parish liaisons that emphasized Catholic teachings on health and social justice, Latino health disparities, spirituality, and methods for planning and implementing EBS.

This menu of capacity-enhancement (CE) activities were delivered by a team of five bilingual (English/Spanish) CRUZA Intervention Specialists with complementary health education, community advocacy, research, and faith-based experience. Two held master's degrees (social work and public health respectively), four were actively involved in their own Latino faith-based communities, and all five were trained by the investigators on human subjects research and study protocols and procedures.

\section{CRUZA's five evidence-based strategies}

Based on recommendations from the US Preventive Services Task Force Community Guide [50], five EBS to promote breast, cervical, colorectal cancer screening included (1) small media; (2) group education; (3) client reminders; (4) reduction of structural barriers to screening; and (5) one-to-one education. To identify components for inclusion in the CRUZA Program Manual and Tool Kit, we thoroughly examined the online archives of Research-Tested Intervention Programs (RTIPS) [51] and Cancer Control P.L.A.N.E.T. (Plan, Link, Act, Network with Evidence-based Tools) [52] for available researchtested intervention protocols under the five EBS. Leading intervention researchers were also identified and subsequently consulted [53, 54] (see Table 1).

Through this process, we identified 28 community intervention programs/protocols designed to increase utilization of breast, cervical, and/or colorectal screening. To be considered as candidates to be included in the CRUZA Program Manual and Toolkit however, each program had to meet two inclusion criteria: (1) cultural and linguistic appropriateness for Spanish-speaking Latinos; and (2) appropriateness for FBOs. As none of the 28 programs identified met both criteria, we leveraged our formative research and community advisory committee expertise and proceeded to adapt and consolidate EBSs following NCl's "Using What Works" guidelines [55] to meet the above criteria while retaining core elements integral to the internal logic of the intervention programs [56].

EBS materials, all written in English and Spanish at the 6th grade level, were packaged into a user-friendly CRUZA Program Manual and Toolkit. The Program Manual offers a step-by-step activity guide for each EBS along with planning tools, sample materials, and resource guides. The toolkit contains EBS materials for easy distribution in parishes: Bible bookmarks, parish bulletin inserts, spiritually themed photo frames with health messages, birthday cards with reminders about

Table 1 CRUZA evidence-based strategies (EBS) and sample materials

\begin{tabular}{|c|c|c|}
\hline EBS & Community guide definitions $^{a}$ & Packaged into CRUZA Toolkit \\
\hline Small media & $\begin{array}{l}\text { Videos and printed materials such as letters, brochures, } \\
\text { and newsletters }\end{array}$ & $\begin{array}{l}\text { - Bookmarks } \\
\text { - Parish bulletin inserts } \\
\text { - Brochures } \\
\text { - Tip sheets } \\
\text { - Posters } \\
\text { - Videos } \\
\text { - Magnets }\end{array}$ \\
\hline Group education & $\begin{array}{l}\text { Presentations, lectures and other interactive formats conducted } \\
\text { by health professionals or trained laypeople }\end{array}$ & $\begin{array}{l}\text { - Guest speakers } \\
\text { - Meet and learn } \\
\text { - CRC Bingo }\end{array}$ \\
\hline Client reminders & $\begin{array}{l}\text { Written or telephone messages advising people that they are } \\
\text { due for screening }\end{array}$ & $\begin{array}{l}\text { - Birthday bulletin inserts } \\
\text { - Birthday cards }\end{array}$ \\
\hline One-to-one education & $\begin{array}{l}\text { Delivery of information by health professionals, lay health } \\
\text { advisors, or volunteers by telephone or in-person in medical } \\
\text { or community settings }\end{array}$ & - Conversations after mass \\
\hline Reducing structural barriers & $\begin{array}{l}\text { Facilitating access by addressing non-economic burdens } \\
\text { that make it difficult for people to access cancer screening } \\
\text { (e.g., distance, time, language) }\end{array}$ & $\begin{array}{l}\text { - Establish partnership with community health center } \\
\text { - Volunteers for transportation and childcare }\end{array}$ \\
\hline
\end{tabular}

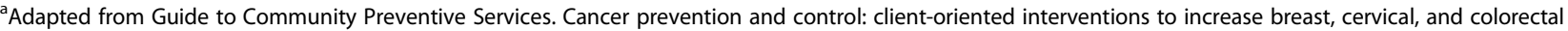
cancer screening. www.thecommunityguide.org/cancer/screening/client-oriented/index.html 
age-appropriate screening guidelines, and bi-fold brochures that weaved family, faith, and health messages [26].

\section{Intervention conditions}

Parishes randomized to the capacity-enhancement (CE) condition received the CRUZA Program Manual and Toolkit, as well as support from CRUZA Intervention Specialists based on a standardized menu of CE activities over a 3-month period of time. Parishes randomized to the standard dissemination (SD) condition received a CRUZA Program Manual and Toolkit; the pastor or designated parish representative in the SD condition was provided with an initial consultation with a CRUZA Intervention Specialist. At the initial consultation meeting (in person or by phone), which lasted between 30 and $60 \mathrm{~min}$, the Intervention Specialist provided instructions for use of the CRUZA Program Manual and Toolkit. This meeting also provided an opportunity for parish representatives to ask questions and to discuss potential barriers to program implementation. While intervention staff did not offer direct assistance with overcoming any of the anticipated barriers, they pointed out materials that were provided in the Program Manual and Toolkit that were designed to help overcome those barriers. Subsequent requests for programmatic assistance from SD parishes during the intervention period were referred to local community resources (e.g., American Cancer Society, community health centers).

\section{Data collection}

\section{Organizational surveys}

There were four sections of the baseline survey, each varied in the content and intended respondent: (1) part A-leadership (pastor); (2) part B-bookkeeping (business manager); (3) part C-Hispanic ministry (director of Hispanic ministry); and (4) part D-health/social services (parish nurse or director of social outreach). Appropriate respondents for each survey component were identified by the pastor. Trained, bilingual survey assistants who were not involved with intervention administration contacted organizational respondents first by phone. When phone attempts were not successful, additional contact strategies included in-person meetings, mail, and email. Baseline organizational surveys took approximately $60 \mathrm{~min}$ to complete (20 min per section) and were conducted between July and December 2012. The follow-up survey, conducted between March and August 2013, took considerably less time (20 $\mathrm{min}$ ) as there was no need to collect data on stable parish characteristics such as congregation size and composition. A detailed description of recruitment methods, sampling procedures, respondent characteristics, and response/completion rates for organizational assessments is available [27].

\section{Process tracking system}

A process tracking system tracked the number and types of interventions offered by parishes. Data for this system was collected from the CRUZA liaisons at each parish on a weekly basis by Intervention Specialists. Liaisons provided information about the type of EBS implemented, the date when implemented, and the number of parish participants reached by the EBS. This system was also used to track the CE dosage (e.g., duration, frequency, amount), type of support (e.g., technical assistance, building health ministries, facilitating inter-organizational linkages, skill-building workshops), and delivery mode (e.g., in-person, phone, email) offered by the Intervention Specialists to each parish. Information about program offerings was also obtained as part of the follow-up surveys administered to all participating parishes.

\section{Measures \\ Primary outcome}

The primary outcome was the mean change in the number of EBS for cancer control offered by parishes between baseline and follow-up by intervention condition. This information was gathered through two sources. First, the baseline and follow-up organizational surveys, which took place approximately 1 year apart, included two open-ended questions adapted from a national study of FBOs [14]. The first question asked, "Has your parish participated in or supported healthrelated projects or programs of any sort to serve the members of your parish within the past twelve months?" When the response was "Yes", a second question was asked, "What health-related projects or programs has your parish sponsored or participated in within the last 12 months?" This data was verified through the process tracking system. Second, information was collected by Intervention Specialists on a weekly basis and recorded in the process tracking system, as described above.

\section{Parish characteristics}

We also assessed parish resources (e.g., size, monetary collections, volunteerism), leader characteristics (e.g., educational level, number of pastoral staff); existing health-related ministries or committees, and existing/ prior inter-organizational ties and collaborations with hospitals or health centers.

\section{Analysis}

Our primary hypothesis was that parishes receiving the $\mathrm{CE}$ intervention would offer a greater number of EBS for cancer control than those in the SD comparison condition. We had originally intended to evaluate this hypothesis with a two-factor mixed ANOVA, using planned contrasts for the interaction of one between-subjects factor (CE vs SD) and one within-subjects factor (repeated measures at baseline 
and follow-up). Sample size calculations were based on assumptions from empirical data that $10 \%$ of FBOs would have offered some form of cancer education program in the prior year and that the intervention would have a small to moderate effect size (0.2-0.4). However, given that only one of the parishes had offered a health program that addressed cancer in the prior year, we were unable to conduct this analysis. Instead, we evaluated differences in the number of EBS at the final survey between intervention conditions with $t$ tests and Pearson's chi-square tests.

\section{Results}

As a requirement for study participation, all parishes had to have completed the baseline survey. Of the 39 parishes that did so (80 \%), 34 (87\%) agreed to participate in the CRUZA trial. Of the 34 parishes randomized to intervention conditions, 3 in the $\mathrm{CE}$ condition did not meet study requirements (i.e., pastor did not meet with CRUZA study staff or did not complete the final survey). This left an analytic sample of $N=31$ parishes (20 in CE and 11 in SD). Of the 31 parishes, approximately three quarters had a Hispanic Ministry, though only a quarter had an organized Health Ministry. Approximately a third (36\%) had offered some form of health program or service in the prior year. Most reported having established relationships with hospitals or health centers, although this mostly reflected sharing communion, prayer and social support by Catholic priests or lay persons in institutional settings, such as hospitals, nursing homes, and prisons, as opposed to health promotion activities. See Table 2 .

\section{Adequacy of randomization procedures in achieving balanced treatment arms}

Independent sample $t$ tests confirmed that there were no significant differences between the intervention groups with respect to financial resources, pastor's socio-demographic characteristics, health program offerings, or levels of existing collaborations with health or social service institutions (see Table 2).

\section{Implementation of EBS for cancer control by intervention condition}

The percentage of parishes in each intervention condition that offered each of the five types of EBS is presented in Table 3. During the study period, most parishes offered one or more of the CRUZA EBS. The most commonly offered intervention was small media. CE parishes offered significantly more small media interventions compared with SD parishes (90 vs $64 \%, p=0.038$ ). With the exception of reduction of structural barriers, a greater proportion of CE parishes offered three of the other EBS types compared with SD parishes (group education 60 vs $36 \%$; client reminders 65 vs $55 \%$; one-to-one educational outreach 70 vs $64 \%$ ), although these differences were not statistically significant. Among the CE parishes, $20 \%$ implemented all five types of EBS, while this was only true for $9 \%$ of SD parishes (data not shown). One of the CE parishes did not participate in any of the CRUZA activities, including the initial consultation. When that parish was removed from the analysis, there was a marginally significant $(p>0.10)$ difference in the group education offerings in CE parishes as compared with SD churches (63 vs $36 \%)$.

\section{Capacity-enhancement dose}

Among CE parishes, work with Intervention Specialists to build health committees was the most common activity, with a mean of 11.5 (range 1-37) instances of capacitybuilding activities offered by CRUZA Intervention Specialists. To a slightly lesser extent, CE parishes engaged in an average of 10.7 contacts for technical assistance (range 031). Fewer Intervention Specialist activities were directed toward facilitating inter-institutional relationships (mean 3.7; range 0-23) and just over half of the parishes (60\%) took advantage of the skill-building workshops. See Table 4.

\section{Discussion}

To our knowledge, this is first randomized trial of an organizational-level intervention aimed at improving capacity among FBOs to implement EBS for cancer control for Latinos [57]. As such, there are several important lessons to be gleaned from this initiative. First, CRUZA attests to the feasibility of conducting a randomized trial to increase uptake of EBS among Catholic parishes serving Latino populations. Second, it suggests that by packaging and appropriately adapting EBS for the intended audience, Catholic parishes are able to offer EBS for their congregations-even without "Specialist" support. Third, while our findings suggest that these parishes have existing capacity to implement EBS for cancer control, even a brief intervention to support their efforts could increase the number and variety of activities that can be implemented.

Few studies have taken rigorous approaches to designing, describing, and evaluating community-based capacity-building intervention strategies, as supported by a recent systematic review that identified and examined 29 empirical studies of capacity-building interventions conducted between 2000 and 2014 [57]. Most of these studies were conducted in school settings or among community coalitions; most targeted individual behaviors such as drinking and substance abuse, sun exposure, and other youth risk behaviors. Only one study that built organizational capacity targeted cancer screening behaviors-a group non-randomized trial evaluating mini-grants and technical assistance 
Table 2 Structural Characteristics of CRUZA parishes by intervention condition, baseline $(n=31)$

\begin{tabular}{|c|c|c|c|c|c|}
\hline & $\begin{array}{l}\text { All parishes } \\
\text { mean/\% (SD) }\end{array}$ & $\begin{array}{l}\text { Capacity enhancement } \\
\text { mean/\% (SD) }\end{array}$ & $\begin{array}{l}\text { Standard dissemination } \\
\text { mean/\% (SD) }\end{array}$ & $p$ value* & $N(C E / S D)$ \\
\hline \multicolumn{6}{|l|}{ Parish resources } \\
\hline Size of congregation & $854(802)$ & $1042(899)$ & $564(538)$ & $0.09^{\mathrm{a}}$ & $17 / 11$ \\
\hline Size of Congregation $(\mathrm{sm})^{\mathrm{b}}$ & $85.7 \%$ & $82.4 \%$ & $90.9 \%$ & $0.53^{c}$ & $17 / 11$ \\
\hline Percent of congregation that is Latino & $43.0 \%$ & $35.5 \%$ & $58.3 \%$ & 0.34 & $19 / 10$ \\
\hline Percent of congregation that volunteer & $7.0 \%$ & $8.4 \%$ & $4.7 \%$ & 0.36 & $19 / 11$ \\
\hline Years of Spanish mass offered & $20.0(14.6)$ & $21.6(16.0)$ & $16.7(11.6)$ & 0.34 & 20/10 \\
\hline \multicolumn{6}{|l|}{ Parish leadership and staff } \\
\hline Number of full-time paid pastoral staff & $6.2(8.1)$ & $7.5(9.7)$ & $3.9(3.6)$ & 0.24 & $19 / 11$ \\
\hline Number of full-time non-pastoral staff & $7.6(8.3)$ & $8.9(9.7)$ & $5.4(4.4)$ & 0.17 & $20 / 11$ \\
\hline Percent of pastors with a graduate degree & $83.3 \%$ & $84.2 \%$ & $81.8 \%$ & 0.87 & $19 / 11$ \\
\hline \multicolumn{6}{|l|}{ Parish programming: health } \\
\hline Hispanic Ministry (y) & $77.4 \%$ & $80.0 \%$ & $72.7 \%$ & 0.64 & 20/11 \\
\hline Organized Health Ministry (y) & $22.6 \%$ & $25.0 \%$ & $18.2 \%$ & 0.66 & $20 / 11$ \\
\hline Offered health program in past year (y) & $35.5 \%$ & $40.0 \%$ & $27.3 \%$ & 0.48 & 20/11 \\
\hline \multicolumn{6}{|l|}{ Existing Collaborations } \\
\hline Partnership with hospitals or health centers & $86.2 \%$ & $89.5 \%$ & $80.0 \%$ & 0.48 & $19 / 10$ \\
\hline
\end{tabular}

Independent $t$ tests; $a=0.05$

${ }^{b}$ Congregation size is based on a cut-off value that is either smaller or larger than 1500

${ }^{c}$ Chi-square test; $a=0.05$

${ }^{*} p$-value compares Capacity Enhancement to Standard Dissemination conditions

on the implementation of Cancer Control Planet EBS in three community-based organizations [58]. And only one study was conducted in church settings - an evaluation of adoption and implementation of the evidence-based Body and Soul program in six churches using mini-grants plus technical assistance [59]. According to the systematic review, only 12 of the 29 empirical capacity-building

Table 3 Percent of CRUZA parishes that implemented EBS for cancer control by intervention condition, final $(n=31)$

\begin{tabular}{|c|c|c|c|}
\hline Strategy & $\begin{array}{l}\text { Capacity } \\
\text { enhancement } \\
(\%)(n=20)\end{array}$ & $\begin{array}{l}\text { Standard } \\
\text { dissemination } \\
(\%)(n=11)\end{array}$ & $p$ value \\
\hline Small media ${ }^{a}$ & 90 & 64 & $0.038^{*}$ \\
\hline Group education ${ }^{\text {b }}$ & 60 & 36 & 0.104 \\
\hline Client reminders ${ }^{c}$ & 65 & 55 & 0.284 \\
\hline $\begin{array}{l}\text { Reduction of } \\
\text { structural barriers }^{d}\end{array}$ & 45 & 55 & 0.305 \\
\hline One-to-one education ${ }^{\mathrm{e}}$ & 70 & 64 & 0.359 \\
\hline \multicolumn{4}{|c|}{$\begin{array}{l}\text { a The Z-Score is } 1.7777 \text {. The } p \text {-value is } 0.03754 \text {. The proportion of Yes or No } \\
\text { responses for Observation } 1 \text { is } 0.9 \text {. The proportion for Observation } 2 \text { is } 0.636 \\
\text { bThe Z-Score is } 1.26 \text {. The } p \text {-value is } 0.10383 \text {. The proportion of Yes or No } \\
\text { responses for Observation } 1 \text { is } 0.6 \text {. The proportion for Observation } 2 \text { is } 0.364 \\
\text { cThe Z-Score is } 0.5718 \text {. The } p \text {-value is } 0.28434 \text {. The proportion of Yes or No } \\
\text { responses for Observation } 1 \text { is } 0.65 \text {. The proportion for Observation } 2 \text { is } 0.545 \\
{ }^{d} \text { The Z-Score is - } 0.5088 \text {. The } p \text {-value is } 0.30503 \text {. The proportion of Yes or No } \\
\text { responses for Observation } 1 \text { is } 0.45 \text {. The proportion for Observation } 2 \text { is } 0.545 \\
\text { eThe Z-Score is } 0.3627 \text {. The } p \text {-value is } 0.35942 \text {.The proportion of Yes or No } \\
\text { responses for Observation } 1 \text { is } 0.7 \text {. The proportion for Observation } 2 \text { is } 0.636 \\
\text { * } p \text {-value compares Capacity Enhancement to Standard Dissemination } \\
\text { conditions }\end{array}$} \\
\hline
\end{tabular}

studies were group randomized trials-the study designs of the remaining 17 included group non-randomized trials, single group pre-post designs, and case studies. Our randomized trial of a capacity-enhancement intervention for EBS in faith-based settings fills a sizeable gap in this literature.

We found that CE parishes in this study offered significantly more small media interventions compared with SD parishes and a greater proportion of CE parishes offered three of the other EBS compared with SD parishes, albeit this latter finding did not reach statistical significance. Our results are somewhat consistent with previous randomized trials on the efficacy of capacitybuilding interventions designed to promote adoption and implementation of EBS. A handful of prior studies found non-significant group differences in adoption

Table 4 Number and types of support provided to capacity enhancement (CE) parishes by CRUZA Intervention Specialists, $n=19$

\begin{tabular}{lll}
\hline Type of support & $\begin{array}{l}\text { Mean (SD) number of } \\
\text { CE activities per parish }\end{array}$ & Range \\
\hline Technical assistance & $10.7(8.7)$ & $0-31$ \\
Health committee or ministry & $11.5(9.0)$ & $1-37$ \\
Inter-organizational relationships & $3.8(7.0)$ & $0-23$ \\
& Percentage & \\
Skill-building workshops & $60 \%$ & \\
\hline
\end{tabular}


rates [60-63], while two studies found significantly higher adoption rates in intervention groups than in comparison groups $[64,65]$. In the first of the two studies that found higher adoption rates following a capacitybuilding intervention, the evidence-based Communities That Care (CTC) prevention system for youth substance abuse, delinquency, and other behaviors was implemented and the 12 intervention communities that received technical assistance via telephone calls, email, and annual site visits had significantly higher adoption of CTC programs than the 12 control communities [64]. In the second study, AIDS service organizations receiving a capacitybuilding package of implementation manuals, staff training workshops, and follow-up consultation resulted in more frequent adoption of evidence-based HIV prevention models [65]. It is important to note that in most capacity-building interventions, technical assistance has typically been proactively provided [34].

Although the CRUZA intervention required that the pastor attend one introductory meeting and designate a liaison to the study, parish liaisons could select the types of support they received from CRUZA Intervention Specialists. Despite our lack of proactive technical assistance and financial incentives, we still found significant increases in uptake of EBS. In CRUZA's case, we offered a menu of capacity-building components to build the skills of members of health ministries and to connect them to other institutions in the local community, but the use of small media was still more widely adopted than any other EBS. These findings suggest the need for further attention to the development of program characteristics of the other EBS-to increase their appeal or enhance their feasibility of use. Indeed, evidence-based programs with more complex components may be more difficult or require more effort to support [35, 38, 66]. However, it is also possible that differences in receipt of capacity-enhancement support among intervention parishes could explain the variations we observed in parish adoption of EBS for cancer control.

We must acknowledge important limitations of this study. With only 31 parishes, we had limited statistical power to detect differences between groups. Our original power calculations were based on two assumptions that did not hold true (i.e., that $10 \%$ of parishes would have offered some form of cancer-related program or activity in the prior year and that few SD parishes would utilize the CRUZA materials). A post hoc power calculation shows that we would have needed a sizeable increase in the number of parishes in each intervention condition to detect a small to moderate effect size or perhaps a nonintervention control group. Our findings are limited in generalizability as we included only one religious denomination. While more than half of Latinos living in the USA self-identify as Catholic, Latinos are increasingly aligning with non-Catholic and nonChristian churches, which typically have different structures and practices [25, 67]. Additional studies may be needed to extend our findings beyond the Catholic parishes enrolled in this trial. Finally, this study would have been strengthened with additional data collection to examine the issue of sustainability. We do not know if CRUZA parishes were able to sustain the level of activity that they demonstrated during the three-month observation period. For instance, the Archdiocese of Boston's Office of Health Care Ministry committed to continuing their support of CRUZA and anecdotal evidence among the CE parishes suggests that some EBS activities were maintained beyond the 3-month study period. Nevertheless, we cannot say for certain that this was the case without a more rigorous evaluation of sustainability.

Despite these limitations, this study provides important information about the potential impact of a short-term, organizational-level intervention designed to promote implementation of EBS for cancer control. We have demonstrated the ability to achieve high response and participation rates among Catholic parishes [27]. Moreover, because we had enumerated all eligible churches in MA and had high participation, we have support for the external validity of our findings within the Catholic church. In addition, this study has a number of implications for public health practice and future research. Most EBS have been developed under "ideal" research conditions and are not packaged for easy uptake by FBOs. Existing interventions tend to be accompanied by implementation manuals written for research protocols, not for the lay public [68]. Moreover, many interventions have not been developed with diverse cultural and linguistic audiences in mind, posing challenges for dissemination efforts targeting FBOs and Latino communities. Findings from this study suggest that adapting existing interventions for cultural, linguistic, and setting characteristics and equipping FBOs with an easy-to-follow implementation guide can result in impressive uptake of EBS, especially when coupled with $\mathrm{CE}$ efforts (e.g., skills training, workshops, etc.) to boost the capacity of FBOs to implement these strategies. In our study, minimal capacity enhancement (3 months) resulted in meaningful increases in the number and types of EBS implemented by parishes and showcase the promise of working with FBOs, particularly Catholic parishes, for implementing EBS for cancer control in Latino communities.

It is important that we do not understate the effort and time that went into identifying, adapting, and translating existing cancer control EBS for delivery in Latino Catholic parishes. We identified few "ready-made," "user-friendly" interventions that could be integrated into the CRUZA Program Manual and Toolkit. These gaps in translational research reinforce the call for well-designed public health 
interventions specifically for diverse audiences, applicable and acceptable for "natural" settings, and scalable without major adaptations or need for high levels of training [69-75].

Further research is also needed to understand the science of capacity building, as it relates to promoting uptake of research-tested interventions for cancer control. The CRUZA trial tested a bundled menu of capacity-enhancement strategies; we did not set out to evaluate which of these components or "ingredients" is most important for enhancing organizational capacity, how these components operate independently and/or together, or to assess the effects of intervention activities on individual-level or group-level competencies. Determining the best ways to impart skills to church lay leaders and volunteers necessary for implementation of EBS may improve the efficiency of future organizationallevel interventions.

\section{Conclusions}

Our findings offer encouraging evidence that packaging and appropriately adapting EBS for cancer control can increase implementation of EBS in Catholic parishes and that even a brief organizational-level intervention to enhance parish capacity to could increase the number and variety of EBS activities that can be implemented for cancer control. This research may serve as a foundation for future comparative studies on the potential contribution of faith-based settings to address cancer and other health disparities among Latinos and other immigrant groups.

\section{Abbreviations \\ CAC: community advisory committee; CBOs: community-based organizations; CE: capacity enhancement; CFIR: consolidated framework for implementation research; CRUZA: Spanish word that literally means "to cross". Its symbolic meaning is explained in the paper; CTC: Communities That Care; EBS: evidence-based strategies; FBOs: faith-based organizations; SD: standard dissemination.}

\section{Competing interests}

The authors declare that they have no competing interests.

\section{Authors' contributions}

JA and MIT conceived of study, lead development of proposal and protocols, drafted the paper, and had final editorial approval. LST, BL, AVG, and HO participated in the development of study protocols, collection and interpretation of data, and manuscript drafts. All authors read and approved the final manuscript.

\footnotetext{
Acknowledgements

This work was supported in part by the National Cancer Institute (U54CA156732, UMASS Boston/Dana-Farber Harvard Cancer Center Comprehensive Cancer Partnership Program), the National Institute on Minority Health and Health Disparities (R21MD005976), and through a cooperative agreement by the Centers for Disease Control and Prevention with the National Cancer Institute (U48DP001946, Massachusetts Cancer Prevention and Control Research Network). The authors gratefully acknowledge the time and insights provided by study participants and our community advisory committee. We also acknowledge the many contributions made by Milagros Abreu, Amanda Bartholomew, Lois Biener,
}

Deb Bowen, Melissa Colon, Daisy Diaz, Karen Emmons, Ericka Gonzalez, Elizabeth Gonzalez Suarez, Elizabeth Harden, Christina Hernandez, Lina Jandorf, Alan Juarez, Ruth Lederman, Laura Linnan, Carol Lowenstein, Hannah Mills, Rosalyn Negron, Aida Palencia, Beninson Peña, John Perez, Luciano Ramos, Lori-Anne Ramsey, Bianka Recinos, Maria Sesma, Sarfaraz Shaikh, Rachel Tsavalakoglou, Emeli Valverde, Bryan Weiner and from the UMASS Boston Center for Survey Research—Scott Mclnerny, Lee Hargraves, Philip Brenner, George Markos.

\section{Author details}

${ }^{1}$ Community Health Program and Department of Public Health and Community Medicine, Tufts University, Medford, MA, USA. ²Dana-Farber Cancer Institute, Boston, MA, USA. ${ }^{3}$ Mauricio Gaston Institute for Latino Community Development and Public Policy, University of Massachusetts, Boston, MA, USA. "Warren Alpert Medical School of Brown University, Providence, RI, USA. ${ }^{5}$ Boston College, Chestnut Hill, MA, USA.

Received: 1 December 2015 Accepted: 29 April 2016

Published online: 18 May 2016

\section{References}

1. Griffith DM, Allen JO, DeLoney EH, Robinson K, Lewis E, Campbell B, Morrels-Samuels S, Sparks A, Zimmerman, MA Reischi T. Community-based organizational capacity building as a strategy to reduce racial health disparities. J Prim Prev. 2010;31(1-2):31-9.

2. Glasgow RE, Chambers DA, Cynkin L. News from the NIH: highlights in implementation science from the national cancer institute and the national institute of mental health. Transl Behav Med. 2013;3(4):335-7.

3. Meissner HI, Glasgow RE, Vinson CA, Chambers D, Brownson RC, Green LW, Ammerman AS, Weiner BJ, Mittman B. The U.S. training institute for dissemination and implementation research in health. Implement Sci. 2013; 8:12-5908-8-12. 10.1186/1748-5908-8-12.

4. Neta G, Sanchez MA, Chambers DA, Phillips SM, Leyva B, Cynkin L, Farrell MM, Heurtin-Roberts S, Vinson C. Implementation science in cancer prevention and control: a decade of grant funding by the national cancer institute and future directions. Implement Sci. 2015;10(1):4. doi:10.1186/ s13012-014-0200-2.

5. Allen JD, Leyva B, Torres Al, Ospino H, Tom L, Rustan S, Bartholomew A. Religious beliefs and cancer screening behaviors among catholic Latinos: implications for faith-based interventions. J Health Care Poor Underserved. 2014;25(2):503-26. doi:10.1353/hpu.2014.0080.

6. Leyva B, Allen JD, Tom LS, Ospino H, Torres MI, Abraido-Lanza AF. Religion, fatalism, and cancer control: a qualitative study among Hispanic Catholics. Am J Health Behav. 2014;38(6):839-49.

7. Torres MI, Marquez DX, Carbone ET, Stacciarini JM, Foster JW. Culturally responsive health promotion in Puerto Rican communities: a structuralist approach. Health Promot Pract. 2008;9(2):149-58. doi:10.1177/ 1524839907307675.

8. Bopp M, Fallon EA. Health and wellness programming in faith-based organizations: a description of a nationwide sample. Health Promot Pract. 2013;14(1):122-31. doi:10.1177/1524839912446478.

9. Campbell MK, Hudson MA, Resnicow K, Blakeney N, Paxton A, Baskin M. Church-based health promotion interventions: evidence and lessons learned. Annu Rev Public Health. 2007;28:213-34.

10. Peterson J, Atwood JR, Yates B. Key elements for church-based health promotion programs: outcome-based literature review. Public Health Nurs. 2002;19(6):401-11.

11. Lasater TM, Becker DM, Hill MN, Gans KM. Synthesis of findings and issues from religious-based cardiovascular disease prevention trials. Ann Epidemiol. 1997;7(7):S46-53.

12. Holt CL, Litaker MS, Scarinci IC, Debnam KJ, McDavid C, McNeal SF, Eloubeidi MA, Crowther M, Bolland J, Martin MY. Spiritually based intervention to increase colorectal cancer screening among African Americans: screening and theory-based outcomes from a randomized trial. Health Educ Behav. 2013:40(4):458-68, doi:10.1177/1090198112459651.

13. Lancaster K, Carter-Edwards L, Grilo S, Shen C, Schoenthaler A. Obesity interventions in African American faith-based organizations: a systematic review. Obes Rev. 2014;15(S4):159-76. 
14. Trinitapoli J, Ellison CG, Boardman JD. US religious congregations and the sponsorship of health-related programs. Soc Sci Med. 2009;68(12):2231-9.

15. Daniels NA, Juarbe T, Moreno-John G, Pérez-Stable EJ. Effectiveness of adult vaccination programs in faith-based organizations. Ethn Dis. 2007;17(1):S1.

16. Davis DT, Bustamante A, Brown CP, Wolde-Tsadik G, Savage EW, Cheng X, Howland L. The urban church and cancer control: a source of social influence in minority communities. Public Health Rep. 1994;109(4):500-6.

17. Duan N, Fox SA, Derose KP, Carson S. Maintaining mammography adherence through telephone counseling in a church-based trial. Am J Public Health. 2000;90(9):1468-71.

18. Jandorf L, Ellison J, Shelton R, Thélémaque L, Castillo A, Mendez El, Horowitz C, Treviño M, Doty B, Hannigan M. Esperanza y vida: A culturally and linguistically customized breast and cervical education program for diverse Latinas at three different united states sites. J Health Commun. 2012;17(2): $160-76$.

19. Lopez VA, Castro FG. Participation and program outcomes in a church-based cancer prevention program for Hispanic women. J Community Health. 2006;31(4):343-62.

20. Sauaia A, Min SJ, Lack D, Apodaca C, Osuna D, Stowe A, MGinnis GF, Latts LM, Byers T. Church-based breast cancer screening education: Impact of two approaches on Latinas enrolled in public and private health insurance plans. Prev Chronic Dis. 2007;4(4):A99.

21. Sauaia A, Welsh AL, Jacobellis J, Min SJ, Byers T. The effect of two church-based interventions on breast cancer screening rates among Medicaid-insured Latinas. Prev Chronic Dis. 2005;2(4):A07.

22. DeHaven MJ, Hunter IB, Wilder L, Walton JW, Berry J. Health programs in faith-based organizations: are they effective? Am J Public Health. 2004;94(6):1030-6.

23. Allicock M, Campbell MK, Valle CG, Barlow JN, Carr C, Meier A, Gizlice Z. Evaluating the implementation of peer counseling in a church-based dietary intervention for African Americans. Patient Educ Couns. 2010;81(1): 37-42.

24. Allicock M, Campbell MK, Valle CG, Carr C, Resnicow K, Gizlice Z. Evaluating the dissemination of body and soul, an evidence-based fruit and vegetable intake intervention: challenges for dissemination and implementation research. J Nutr Educ Behav. 2012;44(6):530-8.

25. PEW Research Center. The shifting religious identity of Latinos in the united states. http://www.pewforum.org/2014/05/07/the-shiftingreligious-identity-of-latinos-in-the-united-states/. Updated 07 May 2014. Accessed 01 Jan 2015.

26. Allen JD, Torres MI, Tom LS, Rustan S, Leyva B, Negron R, Linnan LA, Jandorf $\mathrm{L}$, Ospino $\mathrm{H}$. Enhancing organizational capacity to provide cancer control programs among Latino churches: design and baseline findings of the CRUZA study. BMC Health Serv Res. 2015;15(1):147.

27. Allen JD, Tom LS, Leyva B, Rustan S, Ospino H, Negron R, Torres MI, Galeas AV. Recruiting and surveying catholic parishes for cancer control initiatives: lessons learned from the CRUZA implementation study. Health Promot Pract. 2015. doi: 1524839915582174

28. Allen JD, Pérez JE, Pischke CR, Tom LS, Juarez A, Ospino H, Gonzalez-Suarez E. Dimensions of religiousness and cancer screening behaviors among church-going Latinas. J Relig Health. 2014;53(1):190-203.

29. Allen JD, Pérez JE, Tom L, Leyva B, Diaz D, Torres MI. A pilot test of a church-based intervention to promote multiple cancer-screening behaviors among Latinas. J Cancer Educ. 2014;29(1):136-43.

30. Kenedy PJ \& Sons. The official catholic directory. New York: P.J. Kenedy \& Sons; 2012.

31. Oliver RW. Pastoral teams and parish collaboratives: a case study of diocesan reorganization. The Jurist: Studies in Church Law and Ministry. 2012;72(2):334-76.

32. The Diocese of Worcester. Decrees impact 13 parishes in Worcester diocese. 2010; Retrieved 1 Jan 2014.

33. The Office of Pastoral Planning of the Archdiocese of Boston. Disciples in mission. 2012; Retrieved 1 Jan 2014.

34. Damschroder LJ, Aron DC, Keith RE, Kirsh SR, Alexander JA, Lowery JC. Fostering implementation of health services research findings into practice: a consolidated framework for advancing implementation science. Implement Sci. 2009;4(1):50.

35. Flaspohler P, Duffy J, Wandersman A, Stillman L, Maras MA. Unpacking prevention capacity: an intersection of research-to-practice models and community-centered models. Am J Community Psychol. 2008; 41(3-4):182-96.
36. Chinman M, Hannah G, Wandersman A, Ebener P, Hunter SB, Imm P, Sheldon J. Developing a community science research agenda for building community capacity for effective preventive interventions. Am J Community Psychol. 2005;35(3-4):143-57.

37. Fixsen DL, Naoom SF, Blase KA, Friedman RM. Implementation research: a synthesis of the literature, Tampa Florida University of South Florida Louis de la Parte Florida Mental Health Institute National Implementation Research Network. 2005.

38. Flaspohler PD, Meehan C, Maras MA, Keller KE. Ready, willing, and able: developing a support system to promote implementation of school-based prevention programs. Am J Community Psychol. 2012;50(3-4):428-44.

39. Aspen 520 Institute. Measuring community capacity building: a workbookin-progress for rural communities. https://www.aspeninstitute.org/sites/ default/files/content/docs/csg/Measuring_Community_Capactiy_Building. pdf. Accessed 19 Jan 2015.

40. Baillie E, Bjarnholt C, Gruber M, Hughes R. A capacity-building conceptual framework for public health nutrition practice. Public Health Nutr. 2009; 12(08):1031-8.

41. Crisp BR, Swerissen H, Duckett SJ. Four approaches to capacity building in health: consequences for measurement and accountability. Health Promot Internation. 2000;15(2):99-107.

42. Goodman RM, Speers MA, McLeroy K, Fawcett S, Kegler M, Parker E, Smith SR, Sterling TD, Wallerstein N. Identifying and defining the dimensions of community capacity to provide a basis for measurement. Health Educ Behav. 1998;25(3):258-78.

43. Israel BA, Coombe CM, Cheezum RR, Schulz AJ, McGranaghan RJ, Lichtenstein R, Reyes AG, Clement J, Burris A. Community-based participatory research: a capacity-building approach for policy advocacy aimed at eliminating health disparities. Am J Public Health. 2010;100(11) 2094-102.

44. LaFond AK, Brown L, Macintyre K. Mapping capacity in the health sector: a conceptual framework. Int J Health Plann Manage. 2002;17(1):3-22.

45. Foster-Fishman PG, Berkowitz SL, Lounsbury DW, Jacobson S, Allen NA. Building collaborative capacity in community coalitions: a review and integrative framework. Am J Community Psychol. 2001;29(2):241-61.

46. Minkler M, Wallerstein N. Improving health through community organization and community building. In: Glanz K, editor. Health behavior and health education: theory, research and practice. San Francisco: Josssey-Bass Publishers; 1997. p. Chapter 12.

47. Rothman J. Approaches to community intervention. In: Rothman J, Erlich J, Tropman H, editors. Strategies of community intervention. Itasca: Peacock Publishers; 2001. p. 27-64.

48. Scheirer MA, Dearing JW. An agenda for research on the sustainability of public health programs. Am J Public Health. 2011;101(11):2059.

49. Catanzaro AM, Meador KG, Koenig HG, Kuchibhatla M, Clipp EC. Congregational health ministries: a national study of pastors' views. Public Health Nurs. 2007:24(1):6-17.

50. The Guide to Community Preventative Services. Cancer prevention and control: client-oriented interventions to increase breast, cervical, and colorectal cancer screening. Updated 23 Jan 2014. http://www. thecommunityguide.org/cancer/screening/client-oriented/index.html. Accessed 1 June 2009

51. Research-tested intervention programs (RTIPs). 2014. http://rtips.cancer.gov/ rtips/index.do. Accessed 1 June 2009

52. Cancer control P.L.A.N.E.T. 2014. http://cancercontrolplanet.cancer.gov/index. html. Accessed 1 June 2009.

53. McNeill LH, Coeling M, Puleo E, Suarez EG, Bennett GG, Emmons KM. Colorectal cancer prevention for low-income, sociodemographically-diverse adults in public housing: baseline findings of a randomized controlled trial. BMC Public Health. 2009;9:353-2458-9-353. doi:10.1186/1471-2458-9-353.

54. MIYO: Make it your own. 2014. http://miyoworks.org. Accessed 1 June 2009.

55. Using what works: adapting evidence-based programs to fit your needs. 2014. http://cancercontrol.cancer.gov/use_what_works/start.htm. Accessed 1 April 2014.

56. McKleroy VS, Galbraith JS, Cummings B, Jones P, Harshbarger C, Collins C, Gelaude D, Carey JW, ADAPT Team. Adapting evidence-based behavioral interventions for new settings and target populations. AIDS Educ Prev. 2006; 18(supp):59-73.

57. Leeman J, Calancie L, Hartman MA, Escoffery CT, Herrmann AK, Tague LE, Moore AA, Wilson KM, Schreiner M, Samuel-Hodge C. What strategies are used to build practitioners; capacity to implement community-based 
interventions and are they effective?: a systematic review. Implement Sci. 2015;10(1):80.

58. McCracken JL, Friedman DB, Brandt HM, Adams SA, Xirasagar S, Ureda JR, Mayo RM, Comer K, Evans M, Fedrick D. Findings from the community health intervention program in South Carolina: implications for reducing cancer-related health disparities. J Cancer Educ. 2013;28(3):412-9.

59. Honeycutt S, Carvalho M, Glanz K, Daniel SD, Kegler MC. Research to reality: a process evaluation of a mini-grants program to disseminate evidence-based nutrition programs to rural churches and worksites. J Public Health Manag Pract. 2012;18(5):431-9. doi:10.1097/PHH. 0b013e31822d4c69.

60. Brownson RC, Ballew P, Dieffenderfer B, Haire-Joshu D, Heath GW, Kreuter MW, Myers BA. Evidence-based interventions to promote physical activity: what contributes to dissemination by state health departments. Am J Prev Med. 2007:33(1):S66-78.

61. Buller DB, Reynolds KD, Ashley JL, Buller MK, Kane IL, Stabell CL, Massie KL, Liu X, Cutter GR. Motivating public school districts to adopt sun protection policies: a randomized controlled trial. Am J Prev Med. 2011;41(3):309-16.

62. Hannon PA, Harris JR, Sopher CJ, Kuniyuki A, Ghosh DL, Henderson S, Martin DP, Weaver MR, Williams B, Albano DL. Improving low-wage, midsized employers' health promotion practices: a randomized controlled trial. Am J Prev Med. 2012;43(2):125-33.

63. Glanz K, Steffen A, Elliott T, O'Riordan D. Diffusion of an effective skin cancer prevention program: design, theoretical foundations, and first-year implementation. Health Psychol. 2005;24(5):477.

64. Fagan AA, Hanson K, Briney JS, Hawkins JD. Sustaining the utilization and high quality implementation of tested and effective prevention programs using the communities that care prevention system. Am J Community Psychol. 2012;49(3-4):365-77.

65. Kelly JA, Somlai AM, DiFranceisco WJ, Otto-Salaj LL, McAuliffe TL, Hackl KL, Heckman TG, Holtgrave DR, Rompa D. Bridging the gap between the science and service of HIV prevention: transferring effective research-based HIV prevention interventions to community AIDS service providers. Am J Public Health. 2000;90(7):1082-8.

66. Florin P, Friend KB, Buka S, Egan C, Barovier L, Amodei B. The interactive systems framework applied to the strategic prevention framework: the Rhode Island experience. Am J Community Psychol. 2012:50(3-4):402-14.

67. Ospino H. Hispanic ministry in catholic parishes: a summary report of findings from the national study of catholic parishes with Hispanic ministry. Huntington, IN; 2015. Bilingual edition: English and Spanish

68. Campbell M, Fitzpatrick R, Haines A, Haines A, Kinmonth AL, Sandercock P, Spiegelhalter D, Tyrer P. Framework for design and evaluation of complex interventions to improve health. BMJ. 2000;321(7262):694-6.

69. Napoles AM, Santoyo-Olsson J, Stewart AL. Methods for translating evidence-based behavioral interventions for health-disparity communities. Prev Chronic Dis. 2013;10:E193. doi:10.5888/pcd10.130133.

70. Glasgow RE. What does it mean to be pragmatic? Pragmatic methods, measures, and models to facilitate research translation. Health Educ Behav. 2013;40(3):257-65. doi:10.1177/1090198113486805.

71. Glasgow RE, Vinson C, Chambers D, Khoury MJ, Kaplan RM, Hunter C. National institutes of health approaches to dissemination and implementation science: current and future directions. Am J Public Health. 2012;102(7):1274-81.

72. Glasgow RE, Lichtenstein E, Marcus AC. Why don't we see more translation of health promotion research to practice? Rethinking the efficacy-toeffectiveness transition. Am J Public Health. 2003;93(8):1261-7.

73. Koh HK, Oppenheimer SC, Massin-Short SB, Emmons KM, Geller AC, Viswanath $\mathrm{K}$. Translating research evidence into practice to reduce health disparities: a social determinants approach. Am J Public Health. 2010;100 Suppl 1:S72-80. doi:10.2105/AJPH.2009.167353.

74. Green LW. Closing the chasm between research and practice: evidence of and for change. Health Promot J Austr. 2014;25(1):25-9.

75. Ammerman A, Smith TW, Calancie L. Practice-based evidence in public health: improving reach, relevance, and results. Annu Rev Public Health. 2014:35:47-63.

\section{Submit your next manuscript to BioMed Central and we will help you at every step:}

- We accept pre-submission inquiries

- Our selector tool helps you to find the most relevant journal

- We provide round the clock customer support

- Convenient online submission

- Thorough peer review

- Inclusion in PubMed and all major indexing services

- Maximum visibility for your research

Submit your manuscript at www.biomedcentral.com/submit

) Biomed Central 